Published in final edited form as:

Nat Med. 2006 August ; 12(8): 955-960.

\title{
Memory $T_{H} 2$ cells induce alternatively activated macrophages to mediate protection against nematode parasites
}

\author{
Robert M Anthony ${ }^{1,2}$, Joseph F Urban $\mathrm{Jr}^{3}$, Farhang Alem ${ }^{1}$, Hossein A Hamed ${ }^{1}$, Cristina T \\ Rozo $^{1}$, Jean-Luc Boucher ${ }^{4}$, Nico Van Rooijen ${ }^{5}$, and William C Gause ${ }^{1,2}$ \\ ${ }^{1}$ Department of Medicine, New Jersey Medical School, 185 S. Orange Avenue, Newark, New Jersey 07103, \\ USA ${ }^{2}$ Department of Microbiology, Uniformed Services University of the Health Sciences, 4301 Jones Bridge \\ Road, Bethesda, Maryland 20814, USA ${ }^{3}$ Nutrient Requirements and Functions Laboratory, Beltsville Human \\ Nutrition Research Center, US Department of Agriculture, 10300 Baltimore Avenue, Bldg 307-C CARC- \\ EAST, Beltsville, Maryland 20705, USA ${ }^{4}$ Laboratoire de Chimie et Biochimie Pharmacologiques, Unité Mixte \\ de Recherche 8601, Centre National de la Recherche Scientifique, Université René Descartes, Paris, France \\ ${ }^{5}$ Vrije Universiteit, VUMC, Department of Molecular Cell Biology, Van der Boechorststraat 7, 1081 BT \\ Amsterdam, The Netherlands
}

\begin{abstract}
Although primary and memory responses against bacteria and viruses have been studied extensively, T helper type $2\left(\mathrm{~T}_{\mathrm{H}} 2\right)$ effector mechanisms leading to host protection against helminthic parasites remain elusive ${ }^{1}$. Examination of the intestinal epithelial submucosa of mice after primary and secondary infections by a natural gastrointestinal parasite revealed a distinct immune-cell infiltrate after challenge, featuring interleukin-4-expressing memory $\mathrm{CD}^{+}{ }^{+} \mathrm{T}$ cells that induced IL-4 receptor $^{\text {hi }}\left(\mathrm{IL}^{-} 4 \mathrm{R}^{\mathrm{hi}}\right) \mathrm{CD} 206^{+}$alternatively activated macrophages ${ }^{2}$. In turn, these alternatively activated macrophages (AAMacs) functioned as important effector cells of the protective memory response contributing to parasite elimination, demonstrating a previously unknown mechanism for host protection against intestinal helminths.
\end{abstract}

Productive adaptive immune responses result in $\mathrm{CD}^{+} \mathrm{T}$-cell polarization into effector phenotypes defined by differing cytokine milieus ${ }^{3}$. Helminth parasites and allergens induce $\mathrm{T}_{\mathrm{H}} 2$ responses, including $\mathrm{CD} 4{ }^{+} \mathrm{T}$-cell interleukin (IL)-4 production promoting arginase-1 expression by alternatively activated macrophages (AAMacs) ${ }^{4}$. Although it is known that these AAMacs accumulate during asthmatic inflammation 5 and helminth parasite infections $2,4,6$, 7 , and downregulate type 1 inflammation $2,4,6$, a protective role for them remains undefined.

Infection of mice with the natural mouse gastrointestinal helminth parasite Heligmosomoides polygyrus triggers a highly polarized $\mathrm{T}_{\mathrm{H}} 2$ response ${ }^{1}$. H. polygyrus infection is chronic with established adult worms; if parasites are cleared from the host's intestinal lumen, a rapid, protective $\mathrm{T}_{\mathrm{H}} 2$ memory response operates against challenge infections ${ }^{8}$. Our studies examined early events in this memory response to $H$. polygyrus larvae developing in the intestinal submucosa and indicated that AAMacs have an important role in parasite expulsion.

Correspondence should be addressed to W.C.G. (gausewc@umdnj.edu)

COMPETING INTERESTS STATEMENT

The authors declare that they have no competing financial interests.

Published online at http://www.nature.com/naturemedicine/

Reprints and permissions information is available online at http://npg.nature.com/reprintsandpermissions/

Note: Supplementary information is available on the Nature Medicine website. 
H. polygyrus progresses through distinct environmental niches during infection (Supplementary Fig. 1 online), with tissue-invading larvae developing into adults and migrating into the lumen at day 8 after inoculation (Supplementary Fig. 1). To examine which stages of the protective memory response required $\mathrm{CD} 4^{+} \mathrm{T}$ cells, we administered CD4-specific antibody to mice to deplete $\mathrm{CD}^{+}$cells at specific intervals after secondary infection (Fig. 1a). Administration at early time points (days 0 and 7) resulted in increased worm burden (Fig. 1b), day 7 treatment had intermediate effects, and later treatments (days 9 or 11) had marginal effects, indicating that $\mathrm{CD} 4^{+} \mathrm{T}$ cells are required at early stages of a secondary infection for effective parasite expulsion. This implicated the adaptive immune response during larval development in the intestinal tissue as crucial for host protection. To further confirm that the memory response affects invasive larvae, we recovered muscularis-residing larvae from infected small intestines by using a Baermann apparatus 9 , which provokes premature larval evacuation of the tissue, as an indicator of health and mobility. Significantly fewer larvae were recovered from the tissues of mice with secondary infections than from those with primary infections $(* P<0.001$, Fig. 1c).

Previous studies described a distinct immune cell architecture and increased CD4-dependent $\mathrm{T}_{\mathrm{H}} 2$ cytokine gene expression at the host-parasite interface, with $\mathrm{Gr}-1^{+}$neutrophils accumulating adjacent to the parasite surrounded by a band of $\mathrm{CD}^{+} \mathrm{T}$ cells, and increased CD4-dependent $\mathrm{T}_{\mathrm{H}} 2$ cytokine gene expression observed as early as $4 \mathrm{~d}$ after challenge but not primary inoculation (Fig. 1d) ${ }^{10,11}$. These localized immune cells represent a fraction of the diverse immune cell phenotypes in the intestine, necessitating further analyses of the hostparasite interface through the combined use of immunofluorescence and laser-capture microdissection (IF-LCM). Increased mRNA encoding IL-4 and IL-13 (but not interferon (IFN)- $\gamma$ ) were detected in $\mathrm{CD}^{+}$and $\mathrm{Gr}-1^{+}$populations (Fig. 1e and data not shown). We developed a new approach as described in Methods, for direct detection of IL-4 protein in situ and showed its expression within the band of $\mathrm{CD}^{+} \mathrm{T}$ cells $4 \mathrm{~d}$ after challenge (Fig. 1f). Isotype control antibodies showed minimal nonspecific staining (Fig. 1g); IL-4 protein was not detected at the host-parasite interface $4 \mathrm{~d}$ after primary infection, nor was it detected in challenged IL-4-deficient $\left(I 4^{-/-}\right)$mice or untreated tissues (data not shown). This implies that memory $\mathrm{CD}^{+} \mathrm{T}$ cells secrete IL-4 protein at the host-parasite interface, although it is possible that other leukocytes also express IL-4 in a CD4-dependent manner, as in Nippostrongylus brasiliensis infection ${ }^{12}$.

Although IL-4R $\alpha^{\text {hi }}$ cells surrounding developing $H$. polygyrus larvae $4 \mathrm{~d}$ after challenge did not express a variety of leukocyte markers (Fig. $1 \mathrm{~d}$ and data not shown), infiltrating macrophages (Fig. 1h,i) upregulated the IL-4R $\alpha$ chain, a required component of IL-4Rs (Fig. 1h) and the mannose receptor (CD206; Fig. 1i), characteristic of AAMacs ${ }^{2} . \mathrm{CD}^{+}{ }^{+} \mathrm{T}$ cells (Fig. 2a), IL-4R $\alpha$, macrophages and CD206 (Fig. 2b) at the interface $4 \mathrm{~d}$ after primary infection were markedly reduced. Similar results were observed in C57BL/6 mice (data not shown), indicating that these findings were not strain specific. Decreases in AAMacs were also observed in challenged $\mathrm{Il}^{-/-}$(Supplementary Fig. 2 online) and CD4-depleted mice (Supplementary Fig. 2 ), indicating that IL-4 and memory $\mathrm{CD}^{+} \mathrm{T}$ cells were required for the in vivo accumulation of AAMacs. $\mathrm{F} 4 / 80^{+}$macrophages $4 \mathrm{~d}$ after challenge showed elevated expression of arginase-1 (Fig. 2c), Fizz1 (Fig. 2c) Ym1 and acidic mammalian chitinase (AMCase) and no detectable inducible nitric oxide synthase (iNOS; Fig. 2c), further confirming their alternatively activated state.

To examine whether IL-4R signaling triggered alternative macrophage activation in vivo, we transferred $\mathrm{CD}^{+} \mathrm{T}$ cells from $\mathrm{H}$. polygyrus-cured mice to naive wild-type or Stat $6^{-/-}$(IL-4R defective) recipients. Four days after inoculation, both wild-type and Stat $^{-{ }^{--}}$recipients showed similar Gr- $1^{+}$neutrophil and $\mathrm{CD} 4^{+} \mathrm{T}$ cell infiltrates at the host-parasite interface (Fig. 2d,f). At day 4 after infection, macrophages in wild-type, but not $\operatorname{Stat6}^{-/-}$, recipients showed marked 
upregulation of CD206, as indicated by the yellow cell population (Fig. 2e,g), and had lower parasite and egg burdens (Supplementary Fig. 3 online), as compared to wild type. Arginase-1 expression results in proline production, fibroblast recruitment and subsequent collagen deposition, which are characteristics of $\mathrm{T}_{\mathrm{H}} 2$ inflammation ${ }^{13}$. Collagen deposition was detected at $12 \mathrm{~d}$, but not $4 \mathrm{~d}$, after challenge (Supplementary Fig. 4 online), consistent with inflammation mediated by AAMacs in this microenvironment.

To examine directly whether macrophages mediate protective immunity, we depleted them in vivo by treating mice with clodronate $\left(\mathrm{Cl}_{2} \mathrm{MDP}\right)$-loaded liposomes ${ }^{14}$. Effective worm expulsion was observed in $H$. polygyrus-challenged mice treated with control PBS-loaded liposomes but not in those treated with $\mathrm{Cl}_{2}$ MDP-loaded liposomes (Fig. 3a); similar results were obtained in BL/6 mice (data not shown). Notably, egg burdens remained decreased in $\mathrm{Cl}_{2}$ MDP liposome-treated mice. Challenged mice treated with PBS liposomes yielded significantly fewer recoverable larvae, as determined with the Baermann apparatus, than macrophage-depleted mice at days 4 and 7 after infection $(P<0.01$, Fig. 3b). Examination of the host-parasite interface $4 \mathrm{~d}$ after challenge showed that $\mathrm{F} 4 / 80^{+}$macrophages were selectively depleted from $\mathrm{Cl}_{2} \mathrm{MDP}$ liposome-treated mice (Fig. 3c-f) and that other infiltrating leukocytes were unaffected by either treatment. No significant changes in cytokine gene expression were detected in the draining mesenteric lymph nodes or proximal small intestines of challenged mice receiving either liposome treatment (Fig. $3 \mathrm{~g}$ ), indicating that $\mathrm{CD}^{+}{ }^{+} \mathrm{T}$ cells were appropriately activated.

To further confirm a role for AAMacs in host protection, we administered an arginase inhibitor, $S$-(2-boronoethyl)-1-cysteine (BEC) ${ }^{15}$, to the challenged mice, yielding high parasite burdens, reduced egg burdens at day 14 (Fig. 4a) and enhanced larval recovery at both 4 and $7 \mathrm{~d}$ after challenge (Fig. 4b). To examine the effect of arginase on the parasites directly in situ, we stained parasite cross-sections for cytochrome oxidase (COX) activity, which has been used as an indicator of stress ${ }^{16}$ and observed in several helminths 17,18 . COX staining was markedly increased $7 \mathrm{~d}$ after challenge as compared to that in mice with primary infection or in challenged mice administered BEC (Fig. 4c-f).

Macrophages are usually associated with responses against intracellular pathogens, as their activation via Toll-like receptors and IFN- $\gamma$ results in iNOS expression and microbicidal NO production ${ }^{19,20}$. Exposure to type 2 cytokines promotes arginase- 1 expression and production of polyamines and proline, essential for cellular proliferation and collagen production, respectively 19,21 . Protective arginase- 1 expression has not been described in infectious diseases; previous studies have shown that arginase blockade in vivo promotes intracellular parasite killing by enhancing classical macrophage activation, increasing iNOS activity 15 , 21,22 . Our studies show that arginase also mediates host protective responses, in this case against intestinal nematode parasites. Taken together with the macrophage depletion studies, this indicates that—as in $\mathrm{T}_{\mathrm{H}} 1$ responses - macrophages' activated by $\mathrm{CD} 4^{+} \mathrm{T}$ cells, are an essential effector population in protective $\mathrm{T}_{\mathrm{H}} 2$ responses, and their accumulation during the secondary response is required for parasite clearance, thus providing an evolutionary role for their alternatively activated state. AAMacs have also been found to be protective in schistosomiasis through a quite distinct mechanism, reducing pathology through downregulation of a harmful $\mathrm{T}_{\mathrm{H}} 1$ inflammatory response ${ }^{6}$.

Mechanisms contributing to helminth parasite clearance have remained elusive, although studies have suggested that $\mathrm{T}_{\mathrm{H}} 2$ responses enhance gut contractility and luminal fluid secretion, leading to worm expulsion ${ }^{23-25}$. Also, increased gut epithelial cell turnover promotes expulsion of Trichuris muris ${ }^{26}$, and increased mastocytosis is associated with helminth trickle infection $^{27,28}$. These mechanisms may also be important for $H$. polygyrus, which passes through multiple sites during the course of infection, as the remaining adult parasites in 
challenged mice depleted of macrophages or treated with BEC showed reduced fecundity, suggesting that additional macrophage-independent mechanisms remained intact. Collagen was detected only at later stages of the response, and thus is unlikely to be protective. Although chitinases have been proposed as potential effector molecules in resistance to other parasites ${ }^{29}$, they are probably not important in this system, as neither larval nor adult stages express chitin. Future studies should examine the arginase-dependent protective mechanisms, including potential anti-parasitic factors produced by AAMacs, such as urea and superoxide radicals 22 .

The studies described here suggest a new model for the development of a protective $\mathrm{T}_{\mathrm{H}} 2$ memory response. Memory $\mathrm{CD}^{+} \mathrm{T}$ cells rapidly accumulate at the host-parasite interface and secrete IL-4, inducing localized development of AAMacs recruited to this site. These macrophages impair larval parasite health and mobility through an arginase-dependent pathway, contributing to eventual expulsion of adult worms. These findings could provide insights into protective mechanisms against human tissue-dwelling nematodes that may trigger polarized type 2 inflammation associated with AAMacs, including hepatic Ascaris lumbricoides, lymphatic Filiaria (Brugia malayi), Trichuris trichiura and Anisakis simplex.

\section{Methods}

\section{Mice, parasites and injections}

Female BALB/c (Small Animal Division, National Cancer Institute-Frederick), Il4-/- and Stat $^{-/-}$mice (Jackson Laboratories) were kept under specific pathogen-free conditions in filter top cages in the animal facility at the Beltsville Human Nutrition Research Center, Agricultural Research Service, US Department of Agriculture, and experiments were preformed under the principles set forth in the Guide for the Care and Use of Laboratory Animals, Institute of Animal Resources, National Research Council, Department of Health, Education and Welfare (US National Institutes of Health). We inoculated 200 infective third-stage $H$. polygyrus larvae orally $\left(1^{\prime} \mathrm{Hp}\right)$ into mice as previously described 8 . We treated infected mice with pyrantel pamoate $14 \mathrm{~d}$ after inoculation, to clear the parasites, and shelved them for at least 5 weeks, allowing for the development of resting memory cells. We then reinfected mice $\left(2^{\prime} \mathrm{Hp}\right)$ or used them as donors for memory $\mathrm{CD}^{+} \mathrm{T}$ cells (Hp cured). We treated some mice with $1 \mathrm{mg}$ of antibody to CD4 (GK1.5) or with liposomes, all of which were injected intravenously. We administered liposomes on days $0,1,3,5,7$ and 9. For experiments involving BEC, we gave mice $0.2 \%$ BEC in their drinking water on days $2-11$ after challenge ${ }^{15}$.

\section{Immunohistochemistry}

We prepared small-intestine tissue sections using a Swiss roll method ${ }^{10}$ and stained them as previously described ${ }^{10}$. We used antibodies to the following: Gr-1-FITC, IL-4R $\alpha-\mathrm{PE}$ (M1), CD11c-FITC (BD PharMingen), CD4-Alexa647, F4/80-Alexa647 (Caltag), and CD206FITC (MR5D3; Serotek). We took images $(\times 200)$ on a Zeiss Axiovert 200M microscope (Zeiss), controlled by a TILLVISTRAC imaging system (TILLVISION 4.0 software, TILL Photonic). Some images were taken using a Leica DM6000B microscope with automated stage and Leica DFC350FX camera and were tiled together using Image-Pro stitching software (Media Cybernetics). We normalized exposure times and fluorescence intensities to appropriate control images. We photographed fluorescent channels separately, merged them together and overlaid them atop the corresponding Nomarski images.

For IL-4 in situ staining, we used $20 \mu \mathrm{g} / \mathrm{ml}$ of 11B11-Alexa488 (BD PharMingen) and $10 \mu \mathrm{g} /$ ml BDV6-24G2-Alexa488 (Caltag) in tandem, and normalized results to serial sections stained with $30 \mu \mathrm{g} / \mathrm{ml}$ of rat IgG1-Alexa488 isotype control (BD PharMingen). We added two additional wash steps with $0.5 \%$ Tween-20 in PBS for this procedure. We performed H\&E, 
picrosirius red and cytochrome oxidase staining as previously described 16,21 . Cytochrome oxidase scoring was done by an investigator blinded to the study conditions, by assigning a score of 1-4 (lightest to darkest) to parasite cross-sections.

\section{Immunofluorescent laser capture microdissection (IF-LCM)}

We performed IF-LCM with modifications to previously described methods ${ }^{30}$. Briefly, we stored freshly cut $4-\mu \mathrm{m}$ tissue sections on dry ice until use. We fixed sections in $75 \%$ ethanol for $30 \mathrm{~s}$, air dried them, washed them in PBS, stained them with antibody cocktail $(5 \mu \mathrm{g} / \mathrm{ml}$ F4/80-Alexa647 or $5 \mu \mathrm{g} / \mathrm{ml}$ anti-Gr-1-FITC, plus $20 \mu \mathrm{g} / \mathrm{ml}$ anti-CD4-Alexa647 and 400 units/ $\mathrm{ml}$ RNasin (Promega)) for $30 \mathrm{~s}$, rinsed them in PBS, incubated them in $75 \%$ ethanol for $30 \mathrm{~s}$ and $100 \%$ ethanol for $30 \mathrm{~s}$, and desiccated them by two 1-min xylene incubations. Slides were dissected using PixCell II and CapSureTM LCM Caps (Arcturus Engineering) or LMD6000 (Leica Microsystems) and dissected samples were analyzed by real-time RT-PCR as previously described. Arginase- 1 and iNOS primers and probes were provided by H. Dawson (US Department of Agriculture). Fizz1, Ym1 and AMCase primers were previously described ${ }^{21}$.

\section{Parasite and egg quantification}

For adult parasite burdens, we collected the contents of the small intestines $14 \mathrm{~d}$ after infection, and counted parasites using a dissecting microscope. For egg burdens, we collected fecal contents, loosened them in PBS and counted number of eggs under a light microscope. For larval parasite counts, we collected small intestines, opened them longitudinally and incubated them in PBS at $37^{\circ} \mathrm{C}$ for $3 \mathrm{~h}$ in a Baermann apparatus as previously described ${ }^{9}$. Briefly, intestines collected 4 or $7 \mathrm{~d}$ after infection were placed in a sieve suspended atop a pilsner glass, and parasites that collected at the bottom of the glass were counted.

\section{Liposome-mediated macrophage depletion}

We administered Clodronate $\left(\mathrm{Cl}_{2} \mathrm{MDP}\right)$ - or control PBS-loaded liposomes $(0.2 \mathrm{ml})$ during macrophage-depletion experiments ${ }^{14}$. We generated liposomes as previously described ${ }^{14}$ using phosphatidylcholine (LIPOID E PC; Lipoid GmbH) and cholesterol (Sigma). $\mathrm{Cl}_{2} \mathrm{MDP}$ was a gift of Roche Diagnostics GmbH. We collected mesenteric lymph node (MLN) and proximal small-intestine samples from liposome-treated mice $7 \mathrm{~d}$ after infection, homogenized them in Trizol (Invitrogen) and prepared them for real-time RT-PCR as previously described $^{27}$.

\section{Cell preparations and adoptive transfers}

We isolated $\mathrm{CD} 4^{+} \mathrm{T}$ cells from MLNs of $H$. polygyrus-cured mice as previously described with modifications. We generated single-cell suspensions in RPMI containing 2.5\% FCS and washed them multiple times. We enriched $\mathrm{CD}^{+}$cells using MACS $\mathrm{CD} 4^{+}$beads (Miltenyi Biotech); we injected $5 \times 10^{5}$ cells intravenously into sex- and age-matched recipients, which were infected $2 \mathrm{~d}$ after transfer.

\section{Statistical analysis}

Statistical analyses were preformed using SigmaStat 3.0 (SyStat Software), using Student $t$ tests to compare two groups, ANOVA followed by Tukey post hoc test or Kruskal-Wallis test followed by Dunn post hoc tests to compare multiple groups.

\section{Supplementary Material}

Refer to Web version on PubMed Central for supplementary material. 


\section{Acknowledgements}

The authors would like to thank F.D. Finkelman, S.J. Leibovich and E.J. Allenspach for critically reviewing this manuscript.

\section{References}

1. Gause WC, Urban JF Jr, Stadecker MJ. The immune response to parasitic helminths: insights from murine models. Trends Immunol 2003;24:269-277. [PubMed: 12738422]

2. Noel W, Raes G, Hassanzadeh Ghassabeh G, De Baetselier P, Beschin A. Alternatively activated macrophages during parasite infections. Trends Parasitol 2004;20:126-133. [PubMed: 15036034]

3. Mosmann TR, Cherwinski B, Bond MW, Giedlin MA, Coffman RL. Two types of murine helper T cell clone. I. Definition according to profiles of lymphokine activities and secreted proteins. J Immunol 1986;136:2348-2357. [PubMed: 2419430]

4. Maizels RM, et al. Helminth parasites—masters of regulation. Immunol Rev 2004;201:89-116. [PubMed: 15361235]

5. Zhu Z, et al. Acidic mammalian chitinase in asthmatic Th2 inflammation and IL-13 pathway activation. Science 2004;304:1678-1682. [PubMed: 15192232]

6. Herbert DR, et al. Alternative macrophage activation is essential for survival during schistosomiasis and downmodulates T helper 1 responses and immunopathology. Immunity 2004;20:623-635. [PubMed: 15142530]

7. Loke P, et al. IL-4 dependent alternatively-activated macrophages have a distinctive in vivo gene expression phenotype. BMC Immunol 2002;3:7. [PubMed: 12098359]

8. Urban JF Jr, Katona IM, Paul WE, Finkelman FD. Interleukin 4 is important in protective immunity to a gastrointestinal nematode infection in mice. Proc Natl Acad Sci USA 1991;88:5513-5517. [PubMed: 2062833]

9. Persson L. A modified baermann apparatus for the recovery of infective nematode larvae from herbage and manure. Zentralbl Veterinarmed B 1974;21:483-488. [PubMed: 4411676]

10. Morimoto $\mathrm{M}$, et al. Peripheral CD4 T cells rapidly accumulate at the host:parasite interface and express a polarized Th2 memory response in situ. J Immunol 2004;172:2424-2430. [PubMed: 14764713]

11. Liu Z, et al. Requirements for the development of IL-4-producing T cells during intestinal nematode infections: what it takes to make a Th2 cell in vivo. Immunol Rev 2004;201:57-74. [PubMed: 15361233]

12. Voehringer D, Reese TA, Huang X, Shinkai K, Locksley RM. Type 2 immunity is controlled by IL-4/ IL-13 expression in hematopoietic non-eosinophil cells of the innate immune system. J Exp Med 2006;203:1435-1446. [PubMed: 16702603]

13. Wynn TA. Fibrotic disease and the T(H)1/T(H)2 paradigm. Nat Rev Immunol 2004;4:583-594. [PubMed: 15286725]

14. van Rooijen N, Bakker J, Sanders A. Transient suppression of macrophage functions by liposomeencapsulated drugs. Trends Biotechnol 1997;15:178-185. [PubMed: 9161052]

15. Gobert AP, et al. Protective role of arginase in a mouse model of colitis. J Immunol 2004;173:2109_ 2117. [PubMed: 15265947]

16. Kuwano K, et al. Oxidative stress in lung epithelial cells from patients with idiopathic interstitial pneumonias. Eur Respir J 2003;21:232-240. [PubMed: 12608435]

17. Mei B, Komuniecki R, Komuniecki PR. Localization of cytochrome oxidase and the 2-methyl branched-chain enoyl CoA reductase in muscle and hypodermis of Ascaris suum larvae and adults. J Parasitol 1997;83:760-763. [PubMed: 9267425]

18. Takamiya S, et al. Molecular and functional properties of cytochrome $c$ from adult Ascaris suum muscle. Mol Biochem Parasitol 1996;79:61-70. [PubMed: 8844672]

19. Goerdt S, et al. Alternative versus classical activation of macrophages. Pathobiology 1999;67:222226. [PubMed: 10725788]

20. Mantovani A, Sica A, Locati M. Macrophage polarization comes of age. Immunity 2005;23:344346. [PubMed: 16226499] 
21. Hesse M, et al. Differential regulation of nitric oxide synthase- 2 and arginase- 1 by type $1 /$ type 2 cytokines in vivo: granulomatous pathology is shaped by the pattern of L-arginine metabolism. J Immunol 2001;167:6533-6544. [PubMed: 11714822]

22. Bronte V, Zanovello P. Regulation of immune responses by L-arginine metabolism. Nat Rev Immunol 2005;5:641-654. [PubMed: 16056256]

23. Madden KB, et al. Enteric nematodes induce stereotypic STAT6-dependent alterations in intestinal epithelial cell function. J Immunol 2004;172:5616-5621. [PubMed: 15100305]

24. Shea-Donohue T, et al. The role of IL-4 in Heligmosomoides polygyrus-induced alterations in murine intestinal epithelial cell function. J Immunol 2001;167:2234-2239. [PubMed: 11490010]

25. Zhao A, et al. Dependence of IL-4, IL-13, and nematode-induced alterations in murine small intestinal smooth muscle contractility on Stat6 and enteric nerves. J Immunol 2003;171:948-954. [PubMed: 12847266]

26. Cliffe LJ, et al. Accelerated intestinal epithelial cell turnover: a new mechanism of parasite expulsion. Science 2005;308:1463-1465. [PubMed: 15933199]

27. Ben-Smith A, Lammas DA, Behnke JM. The relative involvement of Th1 and Th2 associated immune responses in the expulsion of a primary infection of Heligmosomoides polygyrus in mice of differing response phenotype. J Helminthol 2003;77:133-146. [PubMed: 12756067]

28. Pennock JL, Grencis RK. The mast cell and gut nematodes: damage and defence. Chem Immunol Allergy 2006;90:128-140. [PubMed: 16210907]

29. Nair MG, et al. Chitinase and Fizz family members are a generalized feature of nematode infection with selective upregulation of Ym1 and Fizz1 by antigen-presenting cells. Infect Immun 2005;73:385-394. [PubMed: 15618176]

30. Murakami H, Liotta L, Star RA. IF-LCM: laser capture microdissection of immunofluorescently defined cells for mRNA analysis rapid communication. Kidney Int 2000;58:1346-1353. [PubMed: 10972700] 

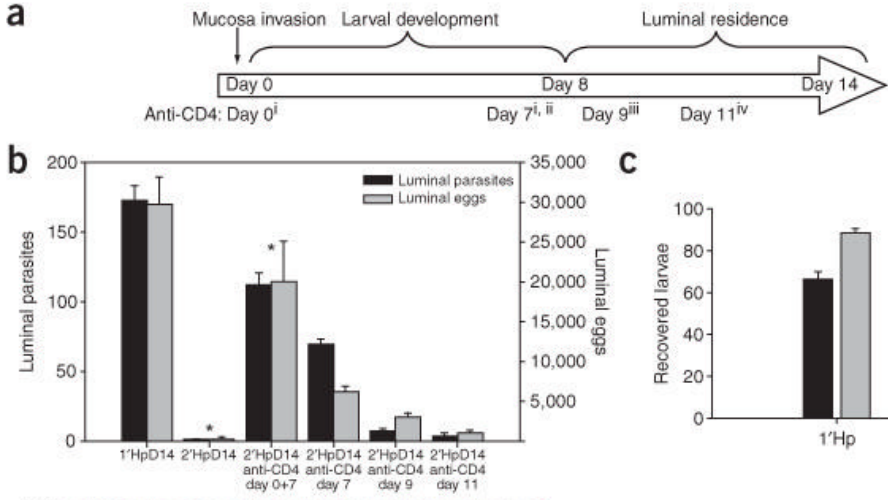

\section{C}
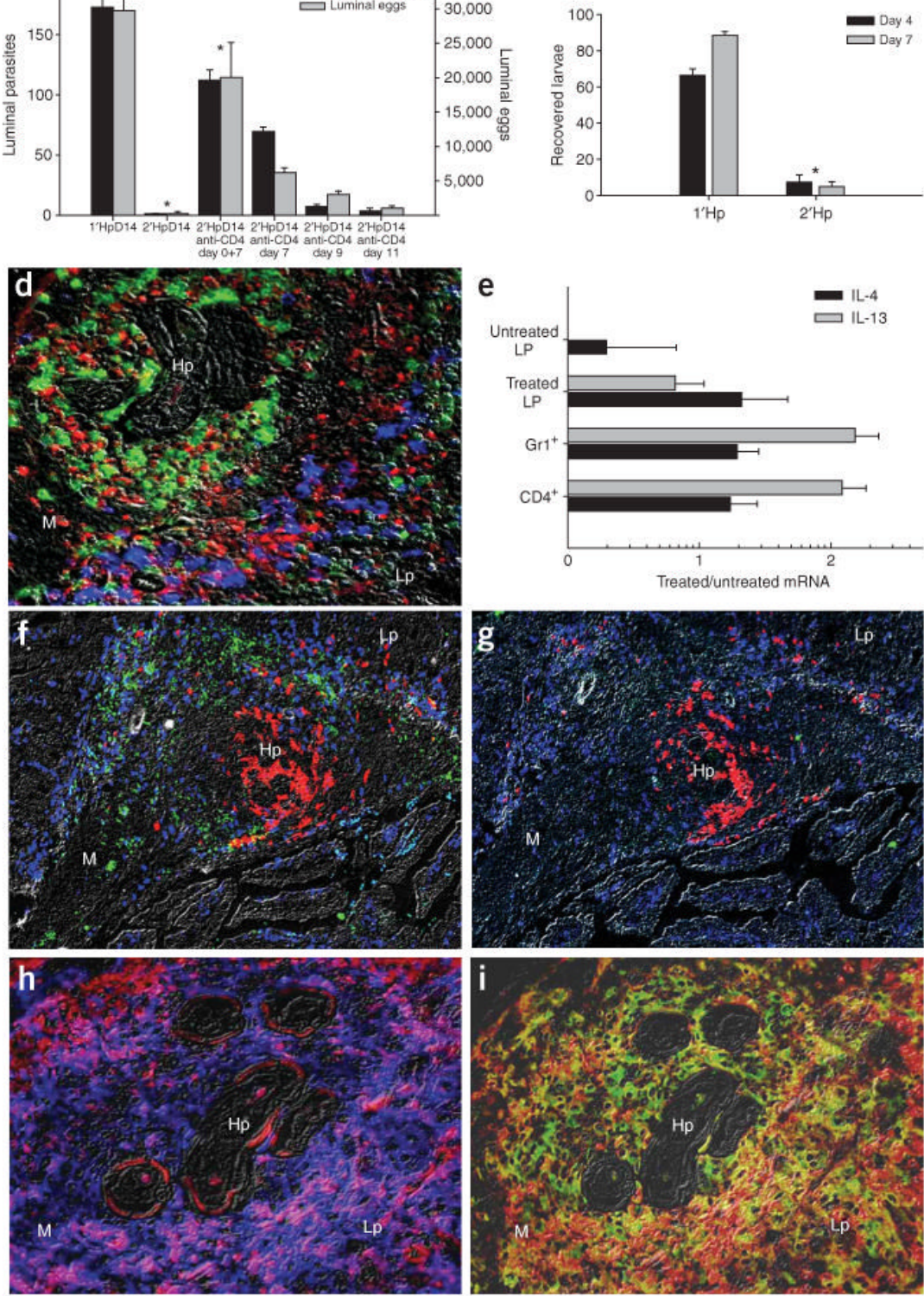

Figure 1.

$\mathrm{CD}^{+} \mathrm{T}$ cell-dependent protective mechanisms occur at early stages after Hp challenge inoculation. (a) Anti-CD4 was administered to challenged mice at days 0 and $7^{(\mathrm{i})}, 7^{\text {(ii) }}, 9^{\text {(iii) }}$ or $11^{\text {(iv) }}$ after inoculation. Treatment group number indicated in parentheses. (b) Worm and egg burdens determined $14 \mathrm{~d}$ after challenge in mice receiving anti-CD4 treatments. Mean and s.e.m. of five mice per treatment group are shown and are representative of three separate experiments. ${ }^{*} P<0.05$ by Kruskal-Wallis test followed by Dunn post hoc test. (c) Parasite larvae recovered from the small intestines of primed or challenged mice using a Baermann apparatus 4 (black bars) and $7 \mathrm{~d}$ (gray bars) after infection. Mean and s.e.m. of four or five mice per treatment group are shown and are representative of three separate experiments. * 
$P<0.001$ by Student $t$-test. (d) Fluorescence immunohistochemistry of the host-parasite interface $4 \mathrm{~d}$ after challenge, showing IL- $4 \mathrm{R} \alpha^{\text {hi }}$ (red) cells encircling the parasite, $\mathrm{Gr}-1^{+}$(green) cells accumulating adjacent to the parasite and $\mathrm{CD}^{+} \mathrm{T}$ (blue) cells surrounding both the parasite and the $\mathrm{Gr}-1^{+}$population (M, muscularis; Lp, lamina propria; Hp, H. polygyrus). (e) Cytokine mRNA expression levels determined by real-time RT-PCR for $\mathrm{CD}^{+}, \mathrm{Gr}-1^{+}$and treated lamina propria $\left(\mathrm{CD}^{-} \mathrm{Gr}^{-} 1^{-}\right)$samples obtained from the host-parasite interface using IF-LCM. Mean and s.e.m. from five mice per treatment group are plotted on a log scale and are representative of two independent experiments. (f) IL-4 protein (green) was detected in situ in the region occupied by $\mathrm{CD} 4^{+} \mathrm{T}$ cells (blue), which surround $\mathrm{Gr}-1^{+}$neutrophils (red). (g) Rat IgG1-Alexa488 isotype control antibody showed minimal nonspecific binding in a serial section of the tissue shown in f. (h) F $4 / 80^{+}$macrophages (blue) costained for the $\mathrm{IL}-4 \mathrm{R} \alpha$ (red), as demonstrated by the ring of purple cells around the parasite. (i) $\mathrm{F} 4 / 80^{+}$ macrophages (red) accumulating at the host-parasite interface expressed CD206 (green), resulting in a yellow-orange stain indicative of their alternatively activated state. 

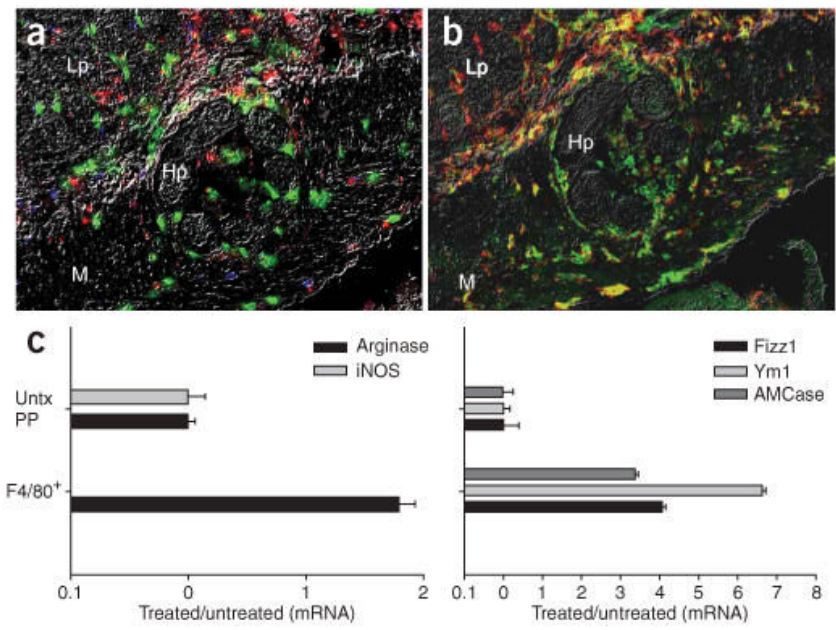
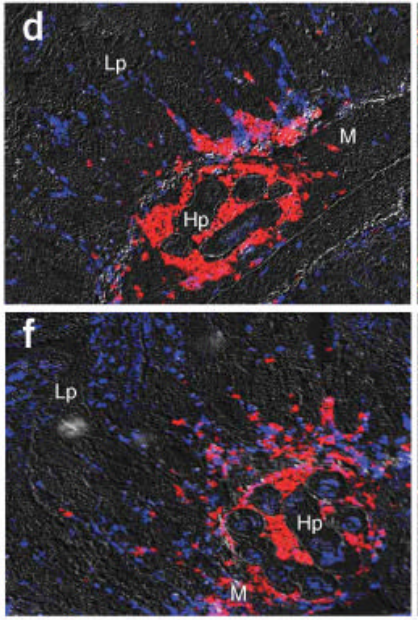
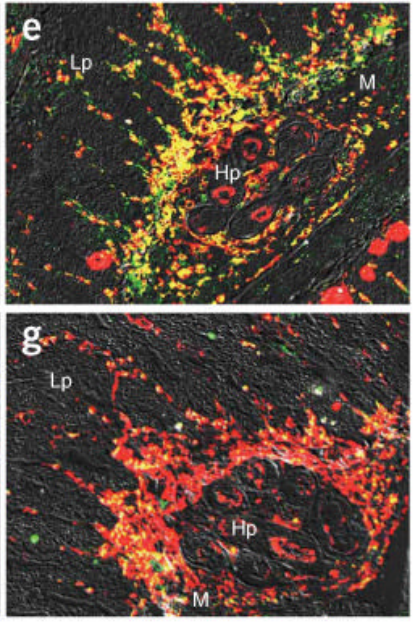

Figure 2.

AAMac accumulation $4 \mathrm{~d}$ after $H$. polygyrus challenge is Stat6 dependent. (a,b) Four days after primary infection, $\mathrm{Gr}-1^{+}$neutrophils (green) accumulated adjacent to the parasite, with substantially fewer $\mathrm{CD} 4^{+} \mathrm{T}$ cells (blue), IL-4R ${ }^{\text {hi }}$ cells (red), F4/80 ${ }^{+}$macrophages (b, red) and CD206 ${ }^{+}$cells (green) compared to what is seen after secondary infection (see Fig. 1d). (c) $\mathrm{F} 4 / 80^{+}$cells dissected from the host-parasite interface by IF-LCM $4 \mathrm{~d}$ after challenge showed gene expression profiles characteristic of AAMacs, including undetectable iNOS (left) and high levels of arginase, Fizz1 (right), Ym1 and AMCase. Mean and s.e.m. of four or five mice per treatment group is plotted on log scales. $(\mathbf{d}-\mathbf{g}) \mathrm{CD}^{+} \mathrm{T}$ cells transferred from $H$. polygyrus-primed mice induced alternatively activated macrophages in wild-type (d,e) but not Stat $6^{-/-}$recipients $(\mathbf{f}, \mathbf{g})$. Gr- $1^{+}$neutrophils (red) and CD4 ${ }^{+} \mathrm{T}$ cells (blue) accumulated around the parasite $4 \mathrm{~d}$ after infection following adoptive transfer of $\mathrm{T}_{\mathrm{H}} 2$ memory cells into wild-type (d) and Stat6 $^{-/-}$(f) recipients. Serial tissue sections show staining for macrophages (F4/80, red) and macrophage mannose receptor (CD206, green), showing that wild-type recipients (e) developed alternatively activated macrophages (yellow), whereas Stat6 ${ }^{-/-}$recipients (g) did not. Lp, lamina propria; m, muscularis; Hp, H. polygyrus. 


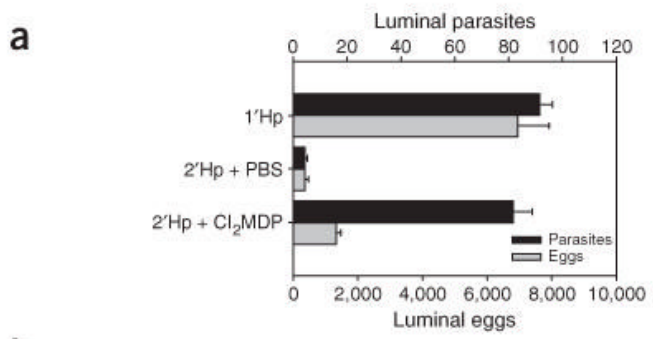

b

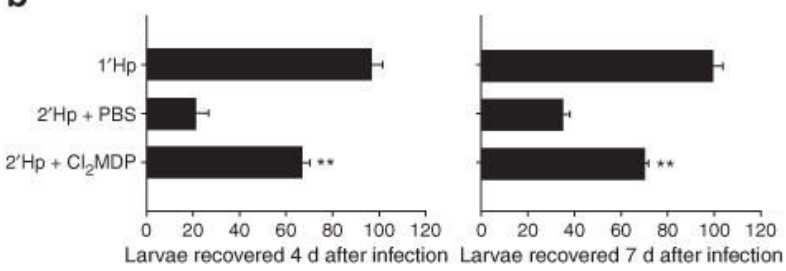

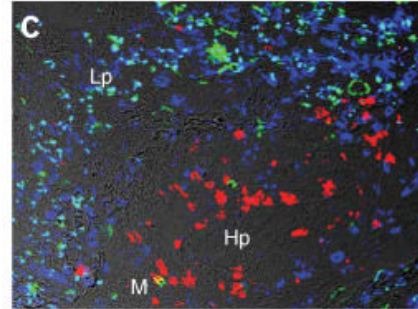
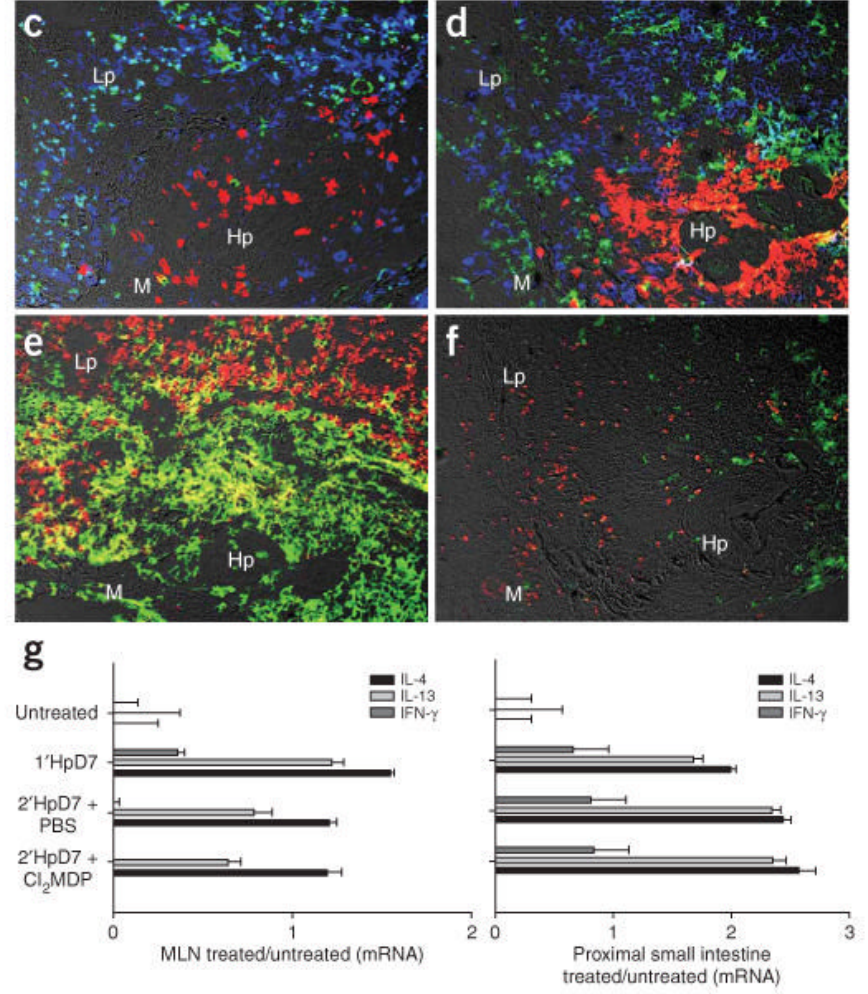

Figure 3.

Macrophage depletion abrogates a protective $\mathrm{T}_{\mathrm{H}} 2$ memory response. (a) Parasite and egg burdens determined $14 \mathrm{~d}$ after challenge in mice treated with $\mathrm{Cl}_{2} \mathrm{MDP}$ or PBS liposomes. (b) Larvae collected using a Baermann apparatus from intestines of challenged mice receiving clodronate or PBS liposome treatment at day 4 and 7 after inoculation. Mean and s.e.m. of five mice per groups are shown; results are representative of three separate experiments. ${ }^{*} P<0.01$ by ANOVA followed by Tukey post hoc test. (c-f) Immunofluorescence of the host-parasite interface $4 \mathrm{~d}$ after challenge showed that neither clodronate (d) nor PBS liposome (c) treatment affected infiltration of $\mathrm{Gr}-1^{+}$(red), $\mathrm{CD}^{+}$(blue) or $\mathrm{CD} 11 \mathrm{c}^{+}$(green) cells at the host-parasite interface. $\mathrm{F} 4 / 80^{+} \mathrm{CD} 206^{+}$macrophages were specifically depleted in the $\mathrm{CL}_{2} \mathrm{MDP}$ liposometreated (f) as compared to the PBS liposome-treated group (e). Cytokine gene expression in mesenteric lymph node (MLN; g, left) and proximal small intestine (right) samples were collected $7 \mathrm{~d}$ after infection, as determined by real-time RT-PCR and plotted on log scales. Lp, lamina propria; m, muscularis; Hp, H. polygyrus. 
a

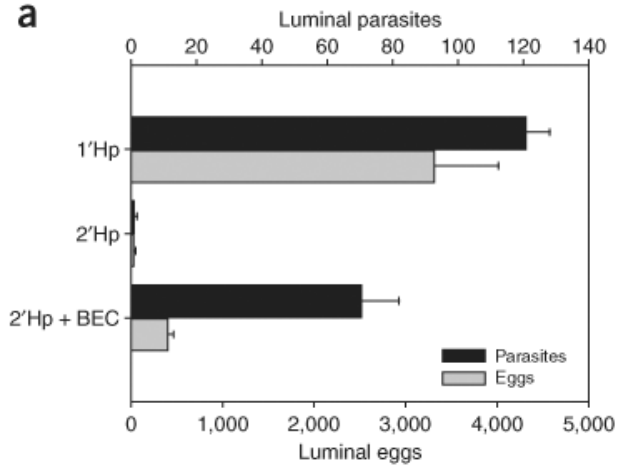

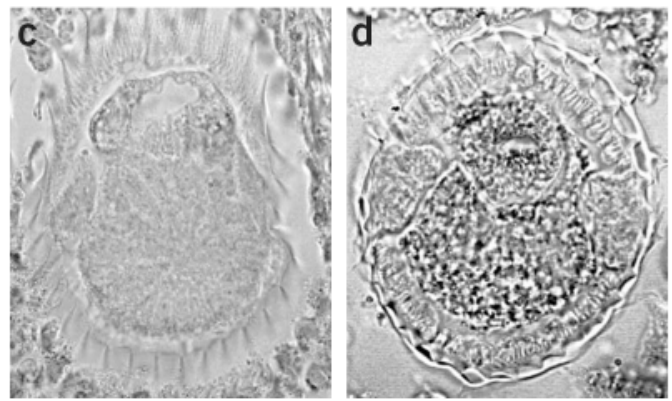
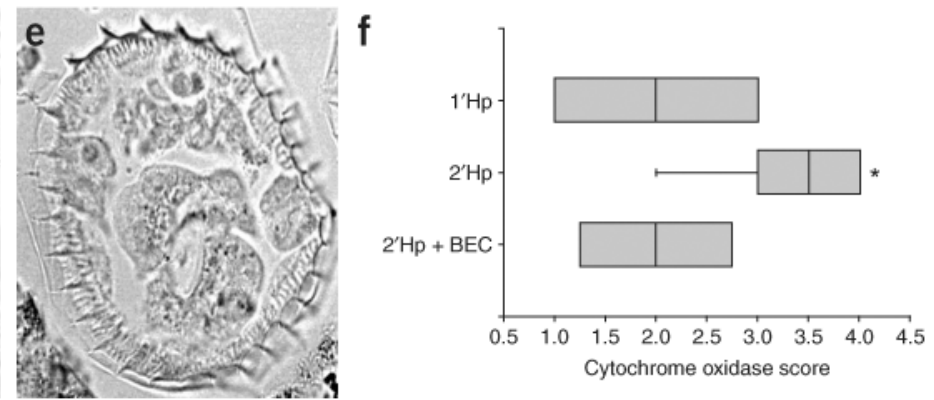

Figure 4.

Arginase inhibition abrogates protective memory response to $H$. polygyrus. (a,b) Shown are parasite and egg burdens determined $14 \mathrm{~d}$ after inoculation (a), and larvae recovered from infected small intestines 4 (b, left) or $7 \mathrm{~d}$ (right) after infection using a Baermann apparatus, in challenged mice that were given $0.2 \% \mathrm{BEC}\left(2^{\prime} \mathrm{HpD} 14+\mathrm{BEC}\right)$ in their drinking water. Bars represent mean and s.e.m. of five mice per group. ${ }^{* *} P<0.001$ and $* P<0.01$ by ANOVA followed by Tukey post hoc test. (c-e) Cytochrome oxidase (black granules) staining of parasite cross-sections $7 \mathrm{~d}$ after primary infection (c), secondary infection (d) and secondary infection with BEC treatment (e). Staining intensity within parasite cross-sections was scored blindly $(1-4$, lightest to darkest). (f) Box plots of scores from four mice per treatment group are plotted. $* P<0.05$ by Kruskal-Wallis test followed by Dunn post hoc test. 